DOI: 10.4274/jarem.galenos.2021.38258

J Acad Res Med 2021;11(2):230-3

\title{
A Rare Cause of Rectal Bleeding in Children Mimicking Rectal Cancer
}

\author{
(1) Burçin Aygün Coşarpınar1, (1) Nafiye Urgancı2, (1) Ramazan Uçak3, (1) Hüseyin Alkım4 \\ ${ }^{1}$ University of Health Sciences Turkey, Şişli Hamidiye Etfal Training and Research Hospital, Clinic of Pediatric, İstanbul, Turkey \\ 2University of Health Sciences Turkey, Şişli Hamidiye Etfal Training and Research Hospital, Clinic of Pediatric Gastroenterology, İstanbul, Turkey \\ ${ }^{3}$ University of Health Sciences Turkey, Şişli Hamidiye Etfal Training and Research Hospital, Clinic of Pathology, İstanbul, Turkey \\ ${ }^{4}$ University of Health Sciences Turkey, Şişli Hamidiye Etfal Training and Research Hospital, Clinic of Gastroenterology, İstanbul, Turkey
}

Cite this article as: Coşarpınar BA, Urgancı N, Uçak R, Alkım H. A Rare Cause of Rectal Bleeding in Children Mimicking Rectal Cancer.

J Acad Res Med 2021;11(2):230-3

\begin{abstract}
Solitary rectal ulcer syndrome is a rare lower gastrointestinal system disease that mainly manifests as rectal bleeding, tenesmus, chronic constipation, straining, and incomplete evacuation. It is usually diagnosed by histopathological examination via biopsy. The lesion takes on various sizes and shapes, ranging from mucosal erythema to single or multiple ulcers, ulcer-nodular lesions, or a polypoid mass. The colonoscopic findings may mimic rectal cancer and inflammatory bowel disease. Treatment of solitary rectal ulcer depends on the severity of the disease and ranges from behavioral therapy to lifestyle modification in mild cases, and medical and surgical procedures in severe refractory cases. Herein, we report on a 17-year-old male patient who presented with rectal bleeding, tenesmus, and constipation and was diagnosed with solitary rectal ulcer.

Keywords: Rectal bleeding, solitary rectal ulcer, rectal tumor
\end{abstract}

\section{INTRODUCTION}

Rectal bleeding is a common symptom of gastrointestinal diseases. The etiology can be classified according to age group. The most common causes are anal fissure, food allergy (allergic colitis), Meckel's diverticulitis, inflammatory bowel disease, colon polyps, vascular malformations, amebiasis, malignancies, bleeding disorders, volvulus, intussusception, HenochSchönlein purpura, hemorrhoids, and solitary rectal ulcer $(1,2)$.

Solitary rectal ulcer syndrome (SRUS) is a rare benign disease, which is generally characterized by rectal bleeding, constipation, difficulty in defecation, abdominal pain, mucus discharge, tenesmus, rectal prolapse, and anemia due to chronic rectal bleeding (3). The estimated incidence of solitary rectal ulcer is approximately $1 / 100,000$ in adults, but rarely it may affect pediatric patients (4). Twenty-six percent of cases are asymptomatic $(1,4)$. A limited number of cases have been reported in the literature, with variable clinical findings (5-7).

Due to the diagnostic challenge posed by SRUS, endoscopic and histological findings are important in suspected cases, in addition to clinical symptoms. Generally, SRUS develops in the anterior rectal wall in about two-thirds of cases. The ulcer can be single, multiple, or circumferential and is usually superficial and non-penetrating. Ulcers become hyperemic and edematous, strict bordered and not extremely superficial in the inner surface of the anal canal. Colonoscopy reveals varying numbers of ulcers or tumoral masses resembling polypoid lesions. Fibromuscular

ORCID IDs of the authors: B.A.C. 0000-0002-4744-1108; N.U. 0000-0003-4854-507X; R.U. 0000-0002-2999-7495; H.A. 0000-0001-7875-0627. 


\section{DISCUSSION}

hyperplasia, smooth muscle cells and collagen infiltration in the lamina propria, thickening of the muscularis mucosa, and crypt structure disruptions on histopathological examination are the main findings that help to distinguish SRUS from ulcerative colitis $(1,8,9)$

Herein, we present a 17-year-old male patient admitted with rectal bleeding, tenesmus, and constipation, diagnosed with solitary rectal ulcer.

\section{CASE PRESENTATION}

A 17-year-old male patient was admitted to the emergency department with a 7-month history of weakness and recent rectal bleeding. Based on his medical history, he had progressively increasing amounts of rectal bleeding and intermittent difficulty in passing stool for the last 5 months, recently accompanied by tenesmus, constipation, and abdominal pain. His weight was $57 \mathrm{~kg}(<3 \mathrm{p})$, and his height was $162 \mathrm{~cm}$ (3-10 p). His general condition was well, and his vital signs were normal. No pathological findings were detected on physical examination. In the initial evaluation, the abdomen was soft, bowel sounds were normal, and there was no hepatosplenomegaly.

Initial laboratory findings were normal (Hemoglobin: 14.8 $\mathrm{mg} / \mathrm{dL}$, hematocrit: 43.4, white blood cells: 8,450 10\%/L, ferritin: $17 \mathrm{ug} / \mathrm{L}$, vitamin B12: $210 \mathrm{ng} / \mathrm{L}$, folic acid: 8.64 ug/L, total protein: $6.2 \mathrm{~g} / \mathrm{L}$, albumin: $3.8 \mathrm{~g} / \mathrm{L}$ ). Additionally, liver and kidney function tests, IgA: $167 \mathrm{mg} / \mathrm{L}, \operatorname{lgG}: 1,030$ $\mathrm{mg} / \mathrm{L}$, IgM: $87 \mathrm{mg} / \mathrm{L}$, tissue transglutaminase IgA: (-), fecal calprotectin: 1,466 $\mu \mathrm{g} / \mathrm{g}, \mathrm{C}$-reactive protein, and coagulation profile were also normal.

Colonoscopic examination revealed a cauliflower-like lobular polypoid formation, which was large enough to fill the lumen up to $10 \mathrm{~cm}$, extending from the anal canal to the lower rectum. The upper parts of the polypoid formations were ulcerated and partially bleeding (Figure 1). Histopathological examination revealed fibromuscular tissue proliferation in the lamina propria indicating a solitary rectal ulcer (Figures 2 and 3$)$.

The patient was conservatively treated with a high-fiber diet, a laxative (lactulose $1 \mathrm{cc} / \mathrm{kg} /$ day divided into three doses), defecation training and a mixture of 5 -aminosalicyclic acid (ASA) $(50 \mathrm{mg} / \mathrm{kg} /$ day, 2 doses), sucralfate $(5 \mathrm{cc} /$ dose, two doses/day), and methylprednisolone $(10 \mathrm{mg} /$ dose, two doses). The rectal bleeding started to decrease following treatment. A follow-up rectosigmoidoscopy was performed after 3 months, and the lesion had improved markedly (Figure 4). When compared with the initial colonoscopic examination, the lesion had shrunk approximately $3 \times 3$ $\mathrm{cm}$, and clinical symptoms improved after treatment (Figure 5). The rectal enema treatment was continued as a single dose. He is still under follow-up in the pediatric gastroenterology clinic.
SRUS is a rare, benign disease of childhood and is generally characterized by rectal bleeding, constipation, tenesmus, abdominal pain, or localized pain in the perineal region. It was first described by Cruveilhier (3) in 1830, and detailed clinical and histopathological characteristics were reported by Madigan and Morson in 1969. The pathogenesis of SRUS is not yet clearly understood. Pressure necrosis of the rectal mucosa due to high intrarectal pressure caused by paradoxical contraction of the pelvic floor, puborectal muscle contractions and rectal mucosal blockage as a result edema and ulcer formation are proposed mechanisms $(4,7)$. Common clinical findings of SRUS are rectal bleeding, mucous passage, tenesmus, and constipation. It is more common in male than in female patients (1-7).

The lack of typical clinical symptoms or atypical signs and symptoms can cause a delayed diagnosis or even misdiagnosis, such as rectal tumoral mass $(6-8,10)$. The diagnosis of SRUS is established by symptoms together with endoscopic and histopathological findings. Since it is quite rare in children, and symptoms are not characteristic, clinicians and pathologists should keep SRUS in mind to prevent diagnostic delays.

The mean duration between symptom onset and diagnosis is 3.2 years and varies between 1.2 and 5 years in pediatric patients, which is shorter than that in adult patients $(1,4)$. Like other similar cases in the literature, our case was also a male patient admitted with rectal bleeding and a recent history of straining and defecation. Different treatment methods were suggested to him, especially for constipation and preliminary diagnosis of anal fissure.

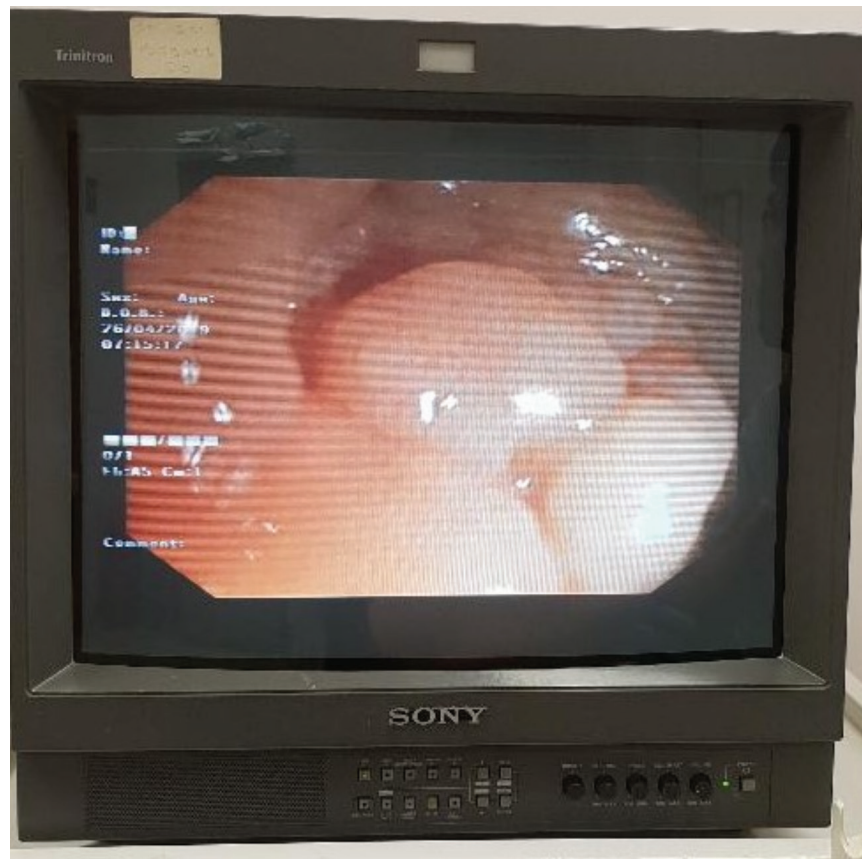

Figure 1. First colonoscopic view with different polypoid lesions 
The sigmoendoscopic findings of SRUS can be detected in three macroscopic types: Ulcerative, polypoid, and hyperemic. The ulcer site does not differ between the three types. The ulcerative form is the most common type in pediatric patients $(60 \%)$, and the most frequent sites are the anterior or anterolateral wall of the rectum, $5-10 \mathrm{~cm}$ proximal to the dentate line. Ulcers are usually $1-1.5 \mathrm{~cm}$ and encircled with hyperemic and edematous mucosa. SRUS cases with a macroscopic polypoid appearance can be misdiagnosed with inflammatory polyp, hyperplastic polyps, or rectal cancer (1,7-9). Since we observed lobular, cauliflower-like, hyperemic surrounded formations in different sizes, starting from the anal canal and filling the lumen up to $10 \mathrm{~cm}$ in the colonic

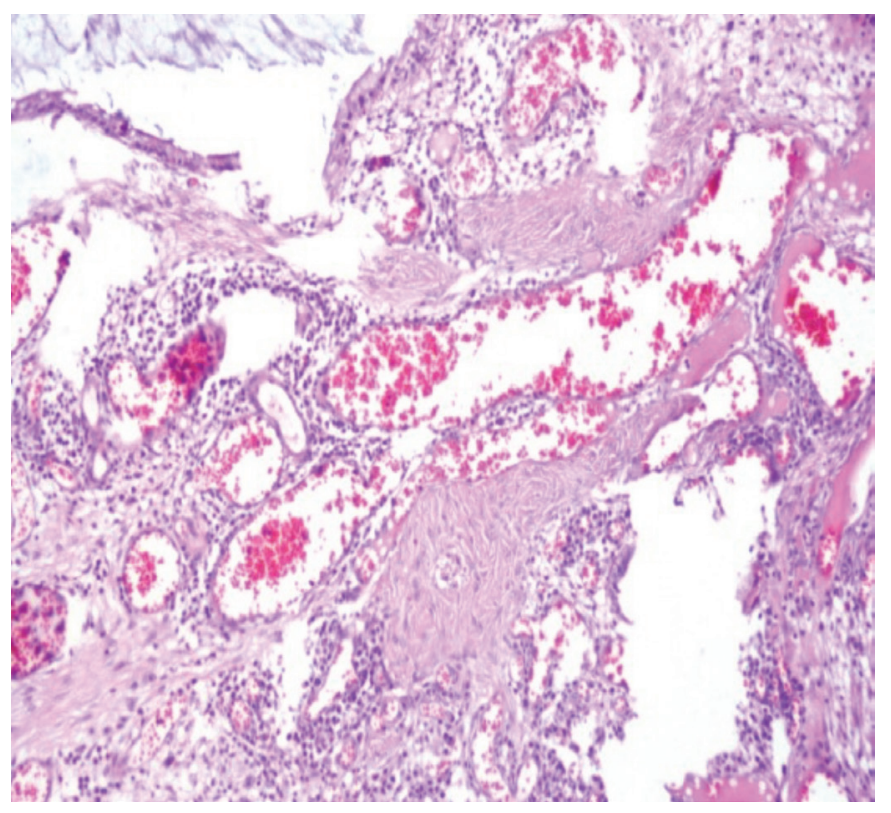

Figure 2. Nonorganized colonic crypts, enlarged vessels, hyperplasia of the lamina propria. Hematoxylin and eosin (H\&E), $100 \times$

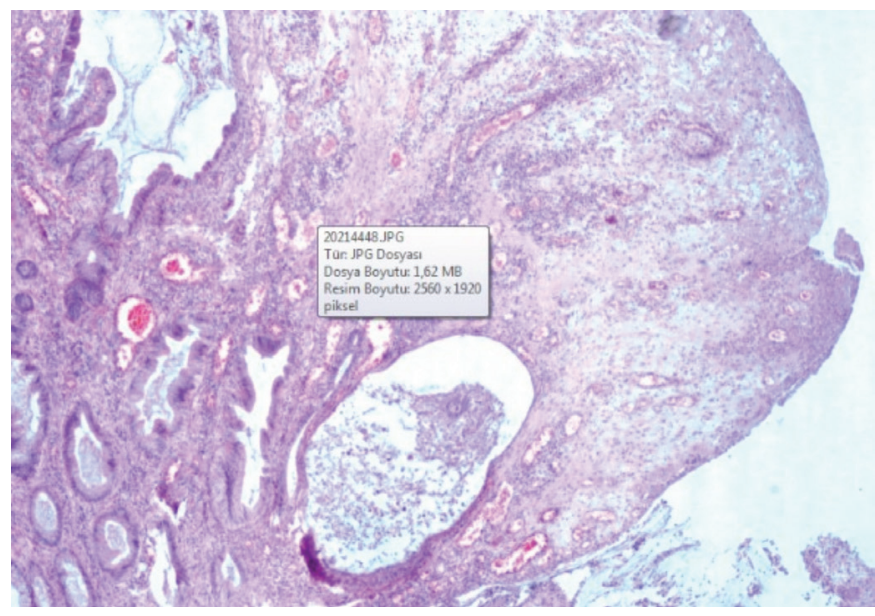

Figure 3. Polypoid granular lesion with ulceration, fibromuscular hyperplasia, filled with mucin and without atypia. H\&E, 40x examination of our case, we thought it might be a tumoral mass. The histopathological examination of biopsy material revealed fibromuscular proliferation in the lamina propria, and a diagnosis of solitary rectal ulcer was made based on clinical, colonoscopic findings and histopathological evaluation.

There is a no standard therapeutic approach for pediatric SRUS patients. The treatment is unique for each patient and the condition quite difficult to manage. Patients and their parents should be informed and convinced that SRUS

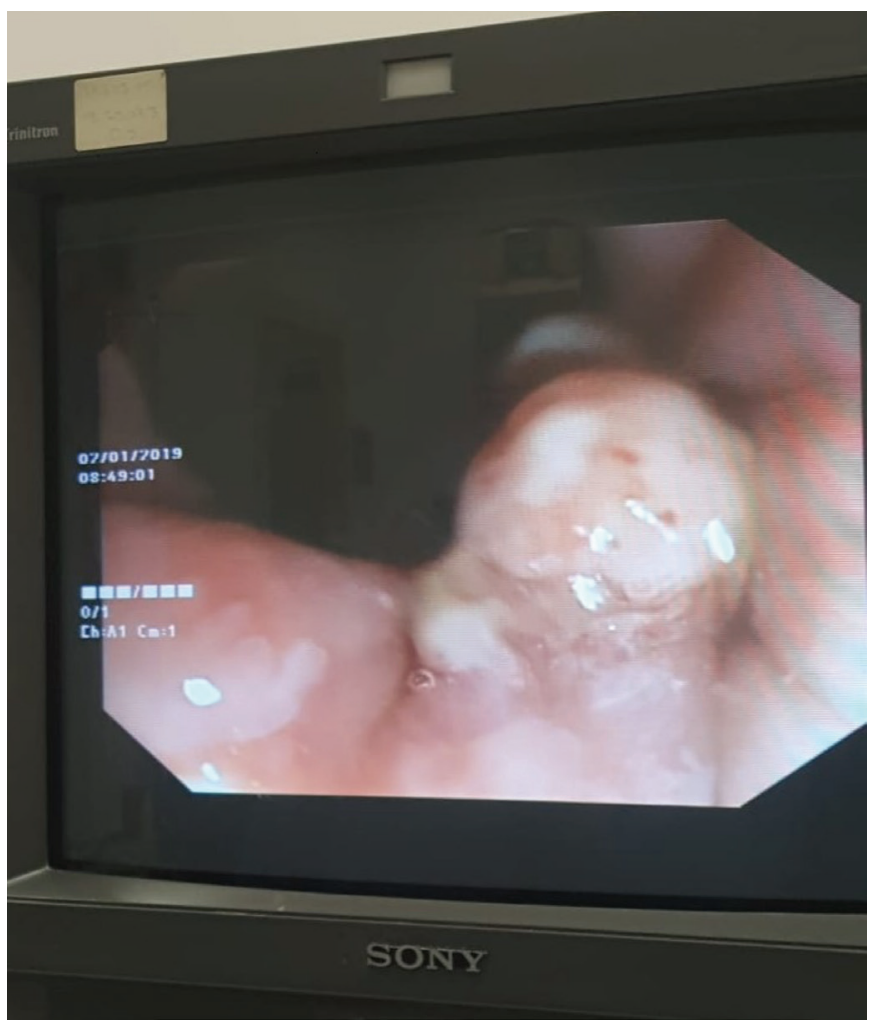

Figure 4. Contraction of the polypoid lesion after 3 months of treatment

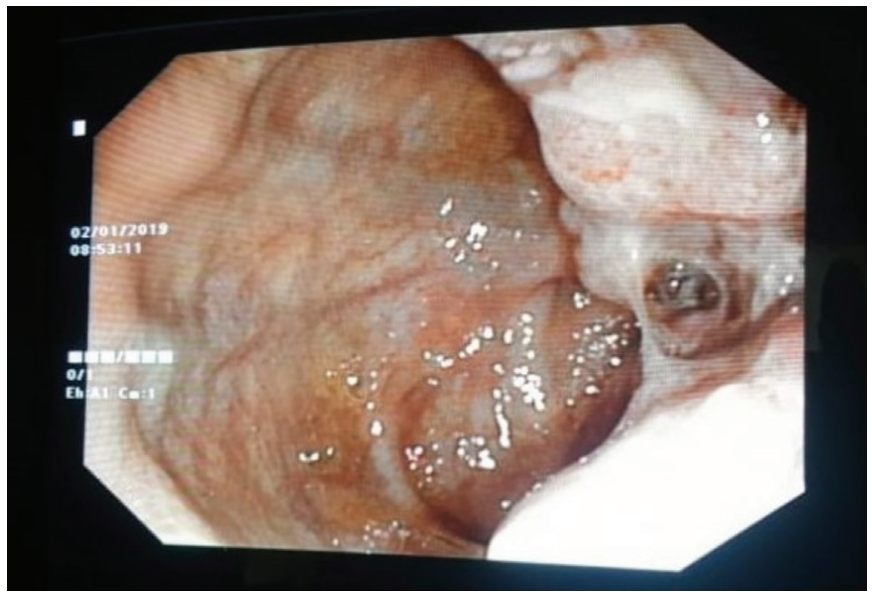

Figure 5. After 6 months of treatment 
Conflict of Interest: The authors have no conflict of interest to declare.

Financial Disclosure: The authors declared that this study has received no financial support.

\section{REFERENCES}

1. Dehghani SM, Malekpour A, Haghighat M. Solitary rectal ulcer syndrome in children: a literature review. World J Gastroenterol 2012; 18: 6541-5.

2. Wong W, Lai K, Shek TW, Lam S. Self-inflicted rectal ulcer with exuberant granulation that mimics carcinoma. Gastrointest Endosc 2002;55:951-2.

3. Cruveilhier J. Ulcere chronique du rectum. In: Anatomie pathologique du corps humain, JB Bailliere, Paris 1829.

4. Blackburn C, McDermott M, Bourke B. Clinical presentation of and outcome for solitary rectal ulcer syndrome in children. J Pediatr Gastroenterol Nutr 2012; 54: 263-5.

5. Dehghani SM, Haghighat M, Imanieh MH, Geramizadeh B. Solitary rectal ulcer syndrome in children: a prospective study of cases from southern Iran. Eur J Gastroenterol Hepatol 2008; 20: 93-5.

6. Urgancı N, Kalyoncu D, Eken KG. Solitary rectal ulcer syndrome in children: a report of six cases. gut liver 2013; 7: 752-5.

7. Thirumal P, Sumathi $B$, Nirmala DA. Clinical entity often missed-solitary rectal ulcer syndrome in children. Front Pediatr 2020; 8: 396.

8. Saadah OI, Al-Hubayshi MS, Ghanem AT. Solitary rectal ulcer syndrome presenting aspolypoid mass lesions in a young girl. World J Gastrointest Oncol 2010; 2: 332-4.

9. Brahim N, Al-Awadhi N, Al-Enezi S, Alsurayei S, Ahmad M. Solitary rectal ulcer syndrome: a clinicopathological study of 13 cases. Saudi J Gastroenterol 2009; 15: 188-92.

10. Somani SK, Ghosh A, Avasthi G, Goyal R, Gupta P. Healing of a bleeding solitary rectal ulcer with multiple sessions of argon plasma. Gastrointest Endosc 2010; 71: 578-82.
Informed Consent: The patient agreed the doctors could use and publish his disease related article with personal information deleted.

Peer-review: Externally and internally peer-reviewed.

Author Contributions: Surgical and Medical Practices - N.U., R.U., H.A.; Concept - B.A.C., N.U.; Design - B.A.C., N.U.; Data Collection and/ or Processing - B.A.C., N.U., R.U., H.A.; Analysis and/or Interpretation B.A.C., N.U., R.U., H.A.; Literature Search - B.A.C.; Writing - B.A.C. 